This item was submitted to Loughborough's Research Repository by the author.

Items in Figshare are protected by copyright, with all rights reserved, unless otherwise indicated.

\title{
As tall as my peers - similarity in body height between migrants and hosts.
}

PLEASE CITE THE PUBLISHED VERSION

https://doi.org/10.1127/anthranz/2018/0828

\section{PUBLISHER}

(c) The authors. Published by E Schweizerbart Science Publishers

\section{VERSION}

VoR (Version of Record)

\section{PUBLISHER STATEMENT}

This work is made available according to the conditions of the Creative Commons Attribution-NonCommercial 4.0 International (CC BY-NC 4.0) licence. Full details of this licence are available at: http://creativecommons.org/licenses/by-nc/4.0/

\section{LICENCE}

CC BY-NC 4.0

\section{REPOSITORY RECORD}

Bogin, Barry, Michael Hermanussen, and Christiane Scheffler. 2019. "As Tall as My Peers - Similarity in Body Height Between Migrants and Hosts.”. figshare. https://hdl.handle.net/2134/28234. 


\title{
As tall as my peers - similarity in body height between migrants and hosts
}

\section{Barry Bogin ${ }^{1}$, Michael Hermanussen ${ }^{2, *}$ and Christiane Scheffler ${ }^{3}$}

\author{
1 Loughborough University, School of Sport, Exercise and Health Sciences, LE11 3TU, UK \\ 2 Aschauhof 3, Eckernförde - Altenhof, Germany \\ 3 University of Potsdam, Institute of Biochemistry and Biology/Human Biology, Potsdam, Germany \\ * Corresponding author: michael.hermanussen@gmail.com, www.michael-hermanussen.de
}

With 2 figures and 2 tables

\begin{abstract}
Background: We define migrants as people who move from their place of birth to a new place of residence. Migration usually is directed by "Push-Pull" factors, for example to escape from poor living conditions or to find more prosperous socio-economic conditions. Migrant children tend to assimilate quickly, and soon perceive themselves as peers within their new social networks. Differences exist between growth of first generation and second generation migrants.

Methods: We review body heights and height distributions of historic and modern migrant populations to test two hypotheses: 1) that migrant and adopted children coming from lower social status localities to higher status localities adjust their height growth toward the mean of the dominant recipient social network, and 2) social dominant colonial and military migrants display growth that significantly surpasses the median height of both the conquered population and the population of origin. Our analytical framework also considered social networks. Recent publications indicate that spatial connectedness (community effects) and social competitiveness can affect human growth.

Results: Migrant children and adolescents of lower social status rapidly adjust in height towards average height of their hosts, but tend to mature earlier, and are prone to overweight. The mean height of colonial/military migrants does surpass that of the conquered and origin population.

Conclusion: Observations on human social networks, non-human animal strategic growth adjustments, and competitive growth processes strengthen the concept of social connectedness being involved in the regulation of human migrant growth.
\end{abstract}

Keywords: growth of migrants, community effect on height, dominance, strategic growth adjustments, competitive growth

\section{Introduction}

This essay focuses on the non-genetic and non-nutritional determinants of adult body height in migrant people. We are particularly interested in the effects on growth of the peer group of a migrant child and adolescent, and how this child perceives being a dominant or a subordinate member within its new social network. The biological aspects of human migration and mobility have extensively been reviewed in Mascie-Taylor \& Krzyżanowska (2017). In view of several definitions of the word 'migrant' in the human biology literature, we define migrants as people who move from one place of residence to another, especially from their place of birth to a geographically and socially new place of residence. This includes people who have migrated within the same country, such as rural-to-urban migrants.

Migration usually is directed by 'Push-Pull' factors (Ravenstein 1885; Ngure et al. 2014). Push and Pull factors can be economic, political, cultural, and environmentally based forces. These Push-Pull factors either induce people to move to a new location or oblige them to leave old residences. Migrants usually leave their original social network and enter new social networks, they may arrive alone, or in groups (Gratton et al. 2007). Migrants tend to identify with their home country and culture (Waldinger 2008), often maintaining cross-border ties to their origin communities (Mouw et al. 2014). They often keep up with traditional values, cultural, ethnic-religious, ethnic-juristic and ethnicpolitical concepts, as well as traditional lifestyle and eating habits. Migration is an arduous process, and staying connected to the homeland is one coping strategy. Adding to the difficulties of the migration process is the fact that many migrants are marginalized and socially disadvantaged in their new communities. Integrating into the local social networks is often difficult and prejudice against the newcomers may lead to ethnic conflicts (Landis \& Alber 2012). Nevertheless, 
most migrants tend to assimilate to some degree in the long run. Assimilation refers to the harmonization of different social groups (up to their fusion) with cultural and structural changes. Cultural assimilation is the process by which the migrant person's or group's culture comes to resemble that of the host. Structural assimilation is a process in which a social or ethnic group gains the same access to structures such as education/law/jobs, as the ruling social or ethnic group.

In summary, migration usually exposes individuals or groups to different cultural conditions, in that the biological and socioeconomic environment differs from that in their place of origin. This transition can produce behavioural and psychological responses, as well as physical changes in the amount and tempo of child growth and attained adult height (Mascie-Taylor \& Krzyżanowska 2017; Bogin 1988). This essay highlights the growth patterns that parallel the cultural transition of migrant children and adolescents. We are particularly interested in migrants who escape from poor or dangerous living conditions to find more prosperous general living and socio-economic conditions, usually with improvements in nutrition, health, housing, water and sanitation (Ngure et al. 2014). These migrants may be classified as "social upgraders" when successfully integrating into the new host population. Adoptees and refugees belong to this group. In contrast, there is another group we are interested in, consisting of migrants who arrive in a new place as conquistadores, colonial rulers, or otherwise psychological, political or economic oppressors, to dominate their host populations.

In this article, we test the hypotheses that:

1. cultural and structural assimilation by "social upgrading" migrants into their new host population is accompanied by adjustments in height growth toward the median height of the hosts. We evaluate cases of migration due to social, economic and political Push-Pull factors including adoptees from low income countries adopted by families in high income countries, and

2. violent, oppressive or military and colonial migration due to conquest is accompanied by height growth that significantly surpasses the median height of both the conquered population and the population of origin.

Human societies can be viewed as networks that can be characterized by nodes (individuals or groups of people), and edges connecting the nodes. The connectivity between people has been studied and not only shows social clustering on emotional traits, on tastes in movies, music, and books, but also on food consumption, obesity, smoking, likelihood of health screening, and other behavioral characteristics (Christakis \& Fowler 2013). Recent Monte-Carlo simulations of body height in an artificial network showed that spatial connectedness can affect height clustering, similar to that seen in natural societies, and further strengthened the concept of connectedness being involved in the regulation of human height (Hermanussen et al. 2014; Hermanussen et al. 2016). These associations are social in nature - they do not depend on genetic relatedness between people - but, are of biological importance in that they produce phenotypic variation that leads to elevated risk for morbidity and mortality (Holt-Lunstad et al. 2010). More recent research finds that social networks influence hormonal activity, including oxytocin and serotonin (Kanat et al. 2013; Dölen et al. 2013) as well as cortisol and testosterone (Kornienko et al. 2014; Kornienko et al. 2016; Ponzi et al. 2016). How social networks may influence growth hormone and insulin-like growth factor-1 is not well researched, but in view of recent work on body size as an expression of social dominance (Bogin et al. 2015; Hermanussen \& Scheffler 2016) we discuss evidence supporting the hypothesis that migrant children can adjust in height toward the average height of their recipient social network, or surpass height of their host and donor populations in cases of violent, oppressive or military and colonial migration.

\section{Material and methods}

We review literature on migrant body heights and body height distributions that is related to social factors. In particular, a Maya population from rural Guatemala that migrated to the United States and rural Bangladeshis who migrated to the United Kingdom, both being strongly influenced by conventional economic, social and political PushPull factors. We also review literature on adoptees moving from India to Sweden and Europeans migrating to the United States and Indonesia, and present historic data on child growth in a colonial dominant European population living in Indonesia.

The Maya-American children considered in this study reside in Indiantown, Florida (a rural community) and Los Angeles, California. The history of Maya immigration into these two communities, described elsewhere by Ashbranner \& Conklin (1986), Burns (1993), Loucky (1996) and Bogin \& Loucky (1997), is here briefly reviewed to provide a general description of the biocultural environment of the refugees of the present study. Civil war in Guatemala from the early 1970 s to 1986 resulted in the death of tens of thousands of Maya and the exodus of more than 250,000 into Mexico and, eventually, into the United States. Despite the civil war and forced migration, most adult Maya migrants to the United States aspire to maintain cultural identity rooted in their formative experiences in rural Guatemala, such as Maya language. Maya refugee children, on the other hand, were born or raised in the United States and most learn both English and Spanish simultaneously, fewer of the refugee children learn their Maya language. While Maya values are still strongly emphasized at home, children are acquiring non-Maya cultural values and behaviours on the streets and in the schools. 
The Maya children measured for this study were between 5.00 and 12.99 years old and belong to the Q'anjob'al language group. Q'anjob'al speakers come from a relatively small region in the northwest Guatemala highlands. Despite their geographic separation in the United States these refugees come from the same ethnic and geographic origin in Guatemala. In Florida children were measured at two primary schools in the years 1992 and 2000. The Los Angeles Maya children were measured at a Christmas party sponsored by a Maya cultural organization in December 1992 and at a community fiesta in 1999. A few children were measured in their homes. In total, for both Indiantown and Los Angles 213 Maya children were measured in 1992 and 431 in 1999-2000. The methodologies for the data collection are described in previous papers (Bogin \& Loucky 1997; Bogin et al. 2002). To compare the growth of Maya-American children with Maya living in their homeland, a sample of 1,353 Guatemala-resident boys and girls living in rural Guatemala villages and measured in 1998 are included in the analysis.

Bangladeshi data come from Houghton et al. (2014) who recruited healthy girls, aged 5-16 years, from schools in Sylhet, Bangladesh (BD) and London, United Kingdom (UK) comprising four groups: Sylhetis $(\mathrm{N}=165)$, first-generation migrants to the UK $(\mathrm{N}=42)$, second-generation girls $(\mathrm{N}=162)$, and British girls of European origin $(\mathrm{N}=50)$.

Body heights of white US Americans of the early-tomid $19^{\text {th }}$ century have been summarized by Komlos \& Cuff (1998). Body height of white South African settlers was reported by Henneberg (2001). Historic data from Australia were obtained from Boyd (1980). Data on body height of colonial Dutch children born and raised in Indonesia were obtained from de Haas (1931) and Gorter \& de Haas (1947). The issue essentially suggests a multivariate data analysis but historic data that allow such analysis, are not available. Therefore, the analysis is confined to descriptive statistics.

\section{Results}

\section{Maya and Bangladeshis}

Fig. 1 provides a modern example of Maya children born and raised in Guatemala versus migrant Maya children, born and raised in two US locations. The figure illustrates the marked improvements in average height of children who migrated to the US. Mean height of children and adolescents aged 5-17 yrs $(\mathrm{N}=1897)$, raised in Guatemala, measured in 1998, was -2.54 SDS below WHO standard/reference (WHO Multicentre Growth Reference Study Group 2006). Mean height SDS of children and adolescents aged 5.00-12.99 yrs $(\mathrm{N}=245)$, raised in Florida and in Los Angeles, California, measured in 1992 was -1.15 SDS. And mean height SDS of children and adolescents aged 5.00-12.99 yrs $(\mathrm{N}=444)$, raised in Florida and Los Angeles, measured in 2000 was only -0.53 SDS below WHO standard/reference (Bogin \& Loucky 1997; Bogin et al. 2002; Smith et al. 2002).
The figure not only shows that migration affects the mean values of height, but also that migration fails to affect the width of the height distribution. Height distributions remain scale invariant, they simply shift to the right, as a whole. The US born children increased in height by more than 10 centimetres within a single generation, but the height difference between the tallest and the shortest within the group remained unchanged. When assuming a Gaussian distribution in height it becomes evident that the width of the three distributions is almost identical. The figure nicely illustrates that people in the same community tend to cluster in height.

Very similar data were published by Houghton et al. (2014) on the Bangladeshis in Bangladesh and London. The study found catch-up growth in height and an acceleration of developmental tempo, measured as age at adrenarche, of first generation migrants, a short final height of first, but not of second generation migrants, and the propensity for overweight. But even though height SDS increased from -1.2 height z-scores in Sylheti, to -0.8 height $z$-scores in the first, and to -0.2 height $z$-scores in the second generation, the standard deviation for height remained almost invariant with 1.3 SD in the Sylheti, 1.0 SD in the first, and 1.3 SD in the second generation indicating that also these girls tend to cluster in height.

\section{Adoptees}

A relatively new type of migrant are adoptees from low income countries, adopted by families in high income countries. In Sweden, over 6800 children from India have been adopted during the last 4 decades (Proos 2009). Upon arrival, most of them were very short, severely undernourished and suffered from infectious illnesses. Many showed a catch-up in height growth. Catch-up growth is a physiological condition of temporary overgrowth, and is indicative of previous growth impairment. It is defined as a height velocity above the statistical limits of normality for age and/or maturity during a defined period of time, following a transient period of growth inhibition (Boersma \& Wit 1997). Catch-up growth occurs after illness, starvation, and psychosocial deprivation, and takes the child back onto his original pre-insult centile or standard deviation score position. Catch-up growth in adoptees is usually accompanied by long lasting developmental acceleration. Particularly, adopted girls tend to prematurely start puberty. Proos (2009) prospectively studied 114 Indian children, adopted in Sweden, over a period of two years. The girls' menarche (first menstruation) was at 11.6 (range of 7.3-14.6) years which was earlier than Swedish (13.0 years) and also earlier than wealthy Indian girls in India (12.4-12.9 years). Also, the adolescent growth spurt of the adoptees was, on average, 1.5 years earlier. The premature onset of pubertal development increased the pace of bone maturation, and in many cases, led to clinically significant reductions in adult height. Final height in these girls was $154 \mathrm{~cm}$ (-1.4 SDS), final weight $46.9 \mathrm{~kg}$ ( $-1.1 \mathrm{SDS})$. Eight percent 

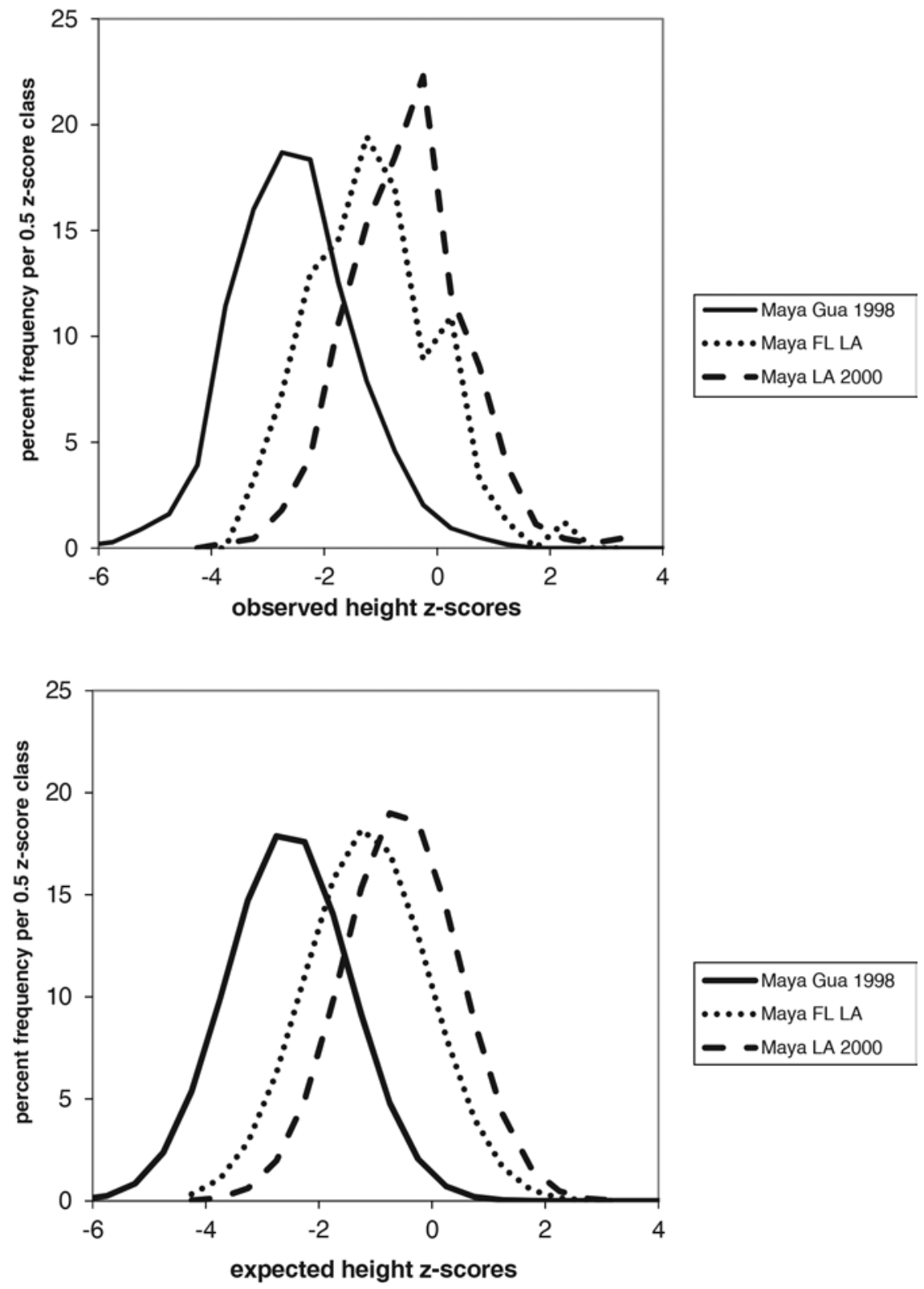

Fig. 1. Height distribution in SDS of Maya children raised in Guatemala $(N=1897)$ in 1998, and in two US locations in $1992(\mathrm{~N}=245)$ and in $2000(\mathrm{~N}=444)$. The top part (observed height $\mathrm{z}$-score distribution) shows percent frequency of height per $0.5 \mathrm{SD}$ class, the bottom part shows calculated percentages assuming a Gaussian distribution in height indicating that the width of the three distributions is almost identical. 'Maya Gua' = Maya living in Guatemala; 'Maya FL LA' = Maya migrants living in Florida and Los Angeles.

of the girls remained $145 \mathrm{~cm}$ or shorter. Boys appeared to be less affected by this acceleration (Proos 2009). This acceleration is difficult to explain, but apart from improvements in health and nutrition, it may also be viewed as an attempt of excessive assimilation in size.

\section{Conquistadores}

Military conquests are a particular form of migration. Conquistadores form the dominant social strata, and they usually take care to ensure that their offspring maintain social dominance. They do not integrate, but rather impose their social networks on their subjects. Colonial Europeans of the $19^{\text {th }}$ and early $20^{\text {th }}$ century were not only taller than their native subjects, but also taller than their continental relatives in Europe. White US Americans of the early-to-mid $19^{\text {th }}$ century surpassed white Europeans by several centimetres (Komlos \& Cuff 1998). American white men in 1860 averaged $174.1 \mathrm{~cm}$, while adult men in England averaged 165.6 $\mathrm{cm}$ and in Sweden and Norway averaged 168.6 (Komlos \& Baur 2004). Greater height for colonists was also true for 
Table 1. Height and height SD of children raised in Brastagi/Indonesia boarding school (1926-1928), compared with height of boys raised in Amsterdam/Netherlands (1916), and in German cities and well situated boys from Frankfurt 1922 (Schlesinger 1926).

\begin{tabular}{|c|c|c|c|c|c|}
\hline \multicolumn{6}{|c|}{ Boys } \\
\hline age & $\begin{array}{c}\text { Brastagi } \\
\text { height }\end{array}$ & (SD) & Amsterdam & German cities & $\begin{array}{c}\text { Frankfurt } \\
\text { well situated }\end{array}$ \\
\hline 6 & 120.9 & 5.5 & 109.1 & & 121.0 \\
\hline 7 & 126.2 & 4.6 & 112.2 & 115.6 & 124.5 \\
\hline 8 & 131.5 & 5.4 & 117.4 & 120.7 & 129.0 \\
\hline 9 & 136.5 & 5.0 & 123.5 & 125.5 & 135.5 \\
\hline 10 & 141.3 & 5.7 & 127.7 & 130.3 & 138.0 \\
\hline 11 & 147.2 & 5.7 & 133.5 & 134.7 & 142.5 \\
\hline 12 & 153.3 & 7.8 & 139.2 & 138.8 & 148.0 \\
\hline \multicolumn{6}{|c|}{ Girls } \\
\hline age & $\begin{array}{c}\text { Brastagi } \\
\text { height }\end{array}$ & (SD) & Amsterdam & German cities & \\
\hline 6 & 116.9 & 3.6 & 108.9 & & \\
\hline 7 & 123.7 & 3.7 & 112.5 & 114.7 & \\
\hline 8 & 129.4 & 4.8 & 118.4 & 119.8 & \\
\hline 9 & 136.2 & 6.6 & 123.4 & 124.7 & \\
\hline 10 & 143.4 & 7.8 & 128.5 & 129.6 & \\
\hline 11 & 148.7 & 6.6 & 132.9 & 134.6 & \\
\hline 12 & 155.8 & 6.9 & 137.8 & 139.7 & \\
\hline
\end{tabular}

white settlers of $19^{\text {th }}$ century South Africa (Henneberg 2001) and Australia (Boyd 1980).

Tall stature also prevailed in the children of colonialists. De Haas \& Gorter (1931) and de Haas (1947) measured Dutch children raised in a boarding school at Brastagi/Indonesia (1926-1928). They were similar in height compared with "tall" US American children (Baldwin 1924), up to $15 \mathrm{~cm}$ taller than German children (measured in 1922 by Schlesinger (1926)), and children raised in Amsterdam (published by Shippers in 1916 (cited after de Haas 1931)) (Table 1), and very much taller than indigenous Indonesian children. It is unlikely that the greater stature of the European colonists and their children is due to better nutrition and health. Indeed, the burden of tropical infections from microorganisms and parasites that are considered responsible for poor growth in many indigenous populations, and likely also affected the offspring of the new colonists, do not exist in Europe.

Instead, we propose that the greater height of the colonial Europeans was in large part due to their self-perception as the dominant social class with a consequent competitive growth and strategic growth adjustment toward greater average height.

\section{Discussion}

Migration results in a series of biological changes in the growth and development, fertility, morbidity, and mortal- ity of migrants and their descendants (Bogin 1988; MascieTaylor \& Krzyżanowska 2017). The biological changes are the result of adaptation and adjustment to the new bio-social environment. The process of adaptation requires behavioural and social flexibility, which are common characteristics of all humans, not just of migrants (Grupe et al. 2012; Lasker 1969).

Migrant assimilation is not a fast-selling item and takes at least one full generation (Bogin 1988). Their assimilation is accompanied by several physical phenomena of which child and adolescent growth is one. Migrant children and adolescents tend to grow faster, they tend to mature earlier and in many cases reach taller adult height than their non-migrant relatives back home (Hermanussen 2013). Differences in child and adolescent growth may be so significant that special growth references have been constructed to better depict the characteristics of migrant growth, such as for Dutch-born Turkish and Moroccan children (Fredriks et al. 2000; Fredriks 2004) and German-born Turkish children (Redlefsen et al. 2007). Migrant children are prone to overweight and obesity and as adults tend to suffer from high prevalence of hypertension, diabetes, chronic kidney disease, obesity and metabolic syndrome (Modesti et al. 2014).

The assimilation in growth of migrants has long been a matter of scientific interest. As early as 1912, Boas (1912) demonstrated the plasticity of human cranial form in US immigrants, challenging traditional doctrines of hereditary, 
Table 2. Height, height SD (cm) and percent difference in height, between Japanese children born in Japan and in the US. Data obtained from Spier (1929).

\begin{tabular}{|c|c|c|c|c|c|c|c|c|c|c|}
\hline \multirow[b]{2}{*}{ Age } & \multicolumn{5}{|c|}{ Boys born in } & \multicolumn{5}{|c|}{ Girls born in } \\
\hline & $\begin{array}{l}\text { Japan } \\
\text { height }\end{array}$ & SD & $\begin{array}{c}\text { US } \\
\text { height }\end{array}$ & SD & $\operatorname{diff} \%$ & $\begin{array}{l}\text { Japan } \\
\text { height }\end{array}$ & SD & $\begin{array}{c}\text { US } \\
\text { height }\end{array}$ & SD & $\operatorname{diff} \%$ \\
\hline 7.5 & 111.0 & 3.4 & 115.5 & 3.6 & 4.0 & 111.4 & 5.1 & 116.4 & 4.8 & 4.5 \\
\hline 8.5 & 117.3 & 4.3 & 120.1 & 5.6 & 2.4 & 115.1 & 4.3 & 117.0 & 4.2 & 1.6 \\
\hline 9.5 & 122.7 & 6.2 & 125.7 & 5.6 & 2.4 & 122.0 & 5.8 & 123.4 & 5.3 & 1.1 \\
\hline 10.5 & 125.6 & 3.9 & 130.0 & 4.4 & 3.4 & 125.2 & 6.4 & 129.6 & 5.1 & 3.5 \\
\hline 11.5 & 131.0 & 3.8 & 135.1 & 5.2 & 3.1 & 133.4 & 7.0 & 136.6 & 7.2 & 2.4 \\
\hline 12.5 & 135.0 & 5.2 & 138.2 & 3.8 & 2.4 & 136.1 & 6.1 & 144.2 & 4.0 & 6.0 \\
\hline 13.5 & 137.6 & 7.0 & 147.7 & 9.1 & 7.4 & 140.1 & 6.3 & 144.8 & 4.9 & 3.3 \\
\hline
\end{tabular}

so-called 'racial', characteristics in the human form. Boas also found parallel changes in body height, and discussed possible explanations, starting from natural selection and selection biases between the groups of American-born and foreign-born children, differences in the numbers of illegitimate children, in social conditions, breaking of more inbred lines, climate, and even mechanical influences such as handling and cradling of infants. Finally, Boas discussed changes in "germplasm", which almost sounds like a vague anticipation of modern epigenetics. Amazingly, Boas did not explicitly discuss nutrition. But noticing the diligence he spent on his work, it seems plausible that he did not overlook the intuitive link between nutrition and growth, but felt that it fails to offer an appropriate explanation for the observed plasticity in human growth. He explicitly stated that "I repeat that I have no solution to offer, that I have only stated the results of my observations and considered the plausibilities of various explanations that suggest themselves, none of which were found satisfactory. Let us await further evidence before committing ourselves to theories that cannot be proven." The likelihood of selective migration, "are migrants taller than sedentes", has been discussed in the literature, and case studies of both selective and random migration are reported (Krzyżanowska \& Mascie-Taylor 2011). The push factors, such as war and poverty, usually affect people without regard to their height. Bogin (1988) discussed rural-tourban migration and found some selection for higher SES that may associate with taller height, but overall, there is not much evidence that migrants are selected for physical traits. Zielińska (1991) analyzed rural-to-urban migration in Poland and reported some selection for greater height when the rural migrants were of very low SES, but no selection when SES was higher.

The link between environment, nutrition and growth is traditional. Louis René Villermé (1782-1863), a French hygienist, used data collected by the military services of the French army in 1812 and 1813 and data from the report to the Minister of War in 1817 (cited by Boyd 1980) and stated that "the stature of man becomes taller, and growth is completed earlier, all things being equal, when the country is rich, and comfort widespread, when clothing and especially food are good, and when difficulties, fatigues and privations experienced in childhood and youth are few. In other words, poverty, that is to say the circumstances accompanying it, produces short stature and retards the period of complete development of the body".

The intuitive link between food and growth remained prevalent in the literature for centuries resulting in the longstanding tradition of claiming changes in nutrition responsible for the bodily changes observed in migrants. Spier (1929) wrote: "The inference is that the observed differences (in growth of Japanese children born in America and in Japan) are due to environmental influences, that is, to influences during the course of growth affecting the American-born in a manner different from those born in Japan" (Table 2). He then narrowed the "environmental influences" to nutrition and continued: "It is generally agreed that such features as stature, which show a considerable increase during the period of growth, are materially affected by nutritional and other factors." This is a sharp contrast to Boas' words, but Spier did not mention sources supporting his statements, nor did he report on his own findings to support his statements on migrant growth. The potential 'eminent role' of nutrition on growth has since been re-echoed many times and is the basis of contemporary nutrient intervention trials to prevent growth stunting (Goudet et al. 2016; Aguayo \& Menon 2016; Hermanussen \& Wit 2017).

Quite in contrast to these textbook lines, numerous historic observations questioned a causal association between nutrition and growth. Koch (1935) explicitly stated that "linear growth has been demonstrated to be almost independent of these two factors (physical exercises and more abundant food). It has neither been possible to achieve height increases by physical exercises, nor does particular abundance of food appear to be a prerequisite for growth at all. Size recklessly increases even during marked undernutrition ... until the body has wasted his last depot". Koch used the term "parasitic growth in length". The statement is amazingly clear for a person who belonged to a generation of physicians that personally experienced the food short- 
ages and starvation in the German population during and shortly after World War I. A knowledgeable summary of observations on human growth during starvation made in the $19^{\text {th }}$ and the first half of the $20^{\text {th }}$ century was provided by Keys et al. (1950) who, too, questioned a causal link between nutrition and growth.

Garrow \& Pike (1967) also questioned the primary role of nutrition as the cause of growth failure. The authors examined 65 Jamaican children 2-8 years after they had been treated for severe malnutrition in a hospital. The former patients were found to be small by North American standards, but not when they were compared with Jamaican children of similar genetical and economic background. A major strength of this study is that Garrow and Pike compared the former patients with their own siblings raised in the same household. This is a good control for genetic and environmental variation. The authors failed to find convincing evidence that a period of severe malnutrition in infancy per se causes stunting of growth in children. In fact they found some evidence for just the opposite, that is, the children who had been hospitalized tended to be taller than their siblings (using sex-age z-scores). The former patients also tended to be faster growing than their siblings and this may be why they were susceptible to severe malnutrition. Garrow \& Pike wrote that, “. . the children who were admitted to hospital were genetically bigger than their siblings. We would suggest that the child whose genetic make-up is such that he would grow very rapidly if well fed, will suffer more on a restricted diet than one with more modest demands. This hypothesis could explain both the fact that in a given family on a restricted diet some children suffer much less harm than others, and also the tendency of the child who has been successfully treated for malnutrition to outgrow his siblings very slightly" (p. 4). The reasons for the more rapid growth of the former patients were not known, but it was certainly not due to greater food intake.

The second important issue to be discussed in migrant growth, is health. It is common wisdom that children from Third World countries suffer from various health impairments among which particularly chronic intestinal inflammation has been associated with growth faltering (Lunn 2000; Campbell et al. 2004). It is thus, intuitive to believe that improvements in health, housing, water and sanitation (Ngure et al. 2014), i.e. in the general living conditions during the process of migration, all of these factors being prerequisites for adequate child growth, may be considered responsible for the growth improvements of migrant children. In contrast to this intuitive belief, convincing longitudinal data in support are still missing. A few studies report that neither Long-chain PUFA supplementation (van der Merwe et al. 2013), nor glutamine-supplementation (Williams et al. 2007), nor early life exposure to antibiotics (Rogawski et al. 2015) had positive effects on growth. A systematic scoping review of interventions promoting better nutrition for infants and children, from birth to age
5.99 years old, living in slums in low income nations identified 22 unique studies of which $16(73 \%)$ were assessed effective (Goudet et al. 2016). Ten of these effective studies increased body mass, especially fat, but had either no impact on stunting (length-for-age $<-2 \mathrm{SD}$ ), or were associated with greater stunting. The 6 interventions with a positive impact on stunting had small effects, with the mean improvement close to the typical value for measurement error. Another systematic review evaluated the effectiveness of urban and rural health and nutrition programmes in low income nations to prevent stunting of under-5 year old infants and children (Hossain et al. 2017). Literature between 1980 and 2015 was searched and only 14 programmes were identified that effectively reduced stunting based on the criteria of an annual rate of reduction $\geq 3 \%$. The authors found that, "Successful interventions were characterised by a combination of political commitment, multi-sectoral collaboration, community engagement, community based service delivery platform, and wider programme coverage and compliance" (p. 1). Single interventions of micronutrient supplementation were not deemed effective.

ACochrane systematic review of interventions to improve water quality, sanitation and hygiene (WASH) practices and their relation to nutritional status was published by Dangour et al. (2013). The authors focused on infants and children under 5 years old and assessed nutritional status as weightfor-height, weight-for-age or height-for-age. The review identified 14 studies meeting the inclusion criteria, involving 22,241 children at baseline and nutrition outcome data for 9,469 children. The authors conducted meta-analyses of the evidence and found no statistically significant effects of WASH interventions on any of the measures of growth in children under five years of age.

\section{Social interactions and their effects on growth in height}

Even if statistical effects are relatively small in many studies, genetics, nutrition, health, and WASH are important determinants of growth and adult body height. These factors interact with wealth, socioeconomic circumstances as well as with social strata, education and professional career, and last but not least, with choice of partners and the genetic make-up of the next generation. The classic interpretation considers optimum nutrition, absence of illness in a hygienic environment, wealth and supportive socio-economic circumstances as the corner stone of growth that will eventually enable the individual to fully reach his genetic target. Fig. 2 illustrates this concept.

We do not debate that nutrition, health, and living conditions influence growth and adult height, but in contrast to the traditional view that these factors are true regulators of growth, we consider these factors as prerequisites that allow for successful growth regulation. Understanding stature as a social signal we consider the regulation of growth 


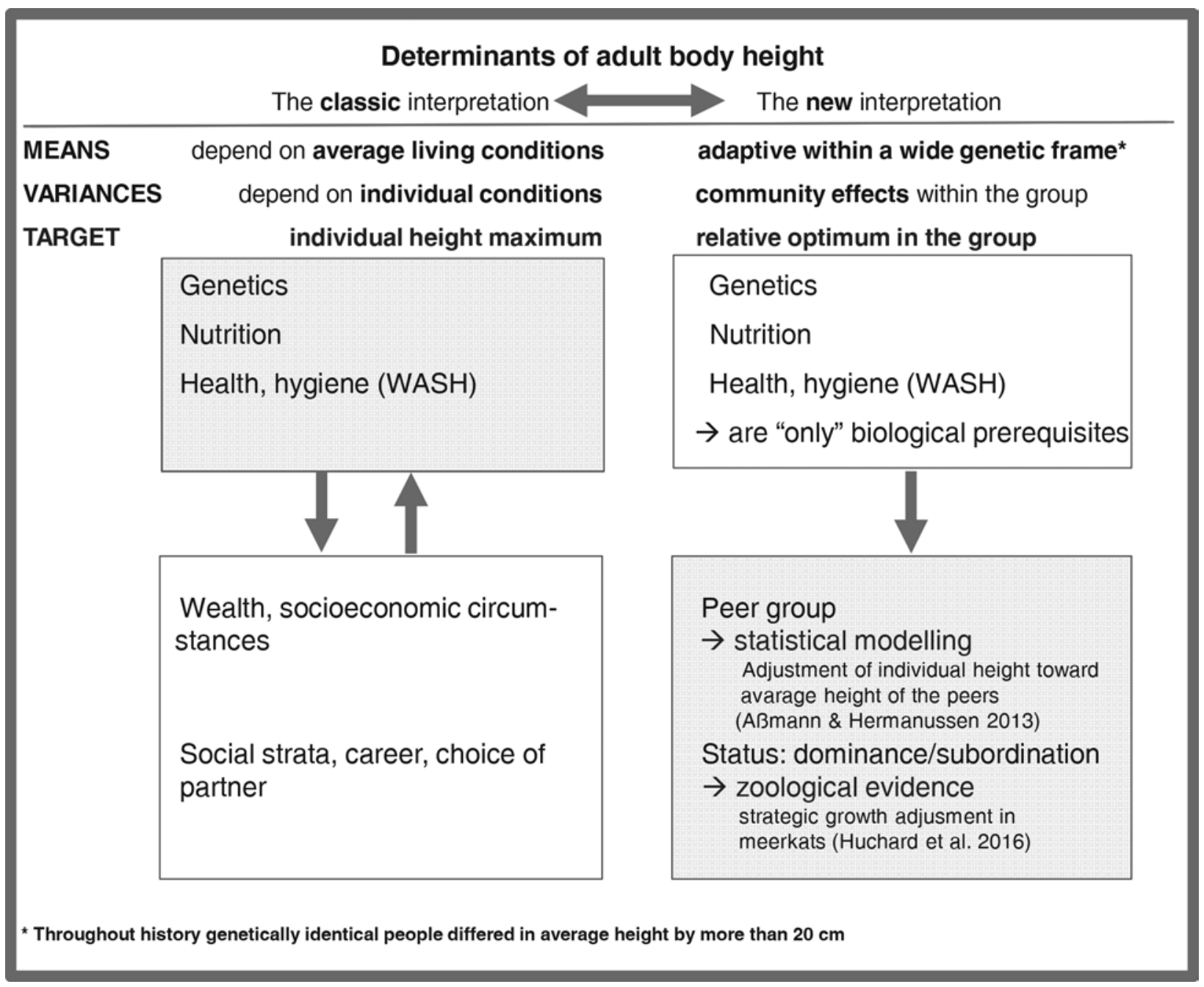

Fig. 2. The determinants of adult body height, comparing the classic interpretation considering genetics nutrition, and health versus the new interpretation, considering community effects within the group.

being influenced by social mechanisms (Hermanussen \& Scheffler 2016). More simply stated, growth is a process that allows for adjusting individual height toward its relative optimum within the group. This social, or community based growth adjustment takes place within a wide genetic frame. Historic evidence suggests that populations may vary in average height by up to $20 \mathrm{~cm}$ within short historic periods of a few generations such as the Dutch secular trend (Floud 1994; Fredriks et al. 2000; NCD Risk Factor Collaboration 2016).

Strong support for growth adjustment within the group is given by the observation that even during periods of marked changes in the mean value for height, the distribution of height remains scale invariant. This is amazing. In a changing world with changing living conditions, it is expected that conditions do usually not change equally for everybody. In addition, inequality should not be limited to inequality of living conditions, also responsiveness to the living conditions is expected to be unequal among different individuals. Those who respond well to improvements should grow better than those who do not. The idea of inequality in the response to inequality in the environment was first brought up by Harrison (1963) who presented an "environmental adversity" hypothesis. The hypothesis implies that poor environmental conditions do not only go along with small mean values for body size but also with larger standard deviations for size. The hypothesis was supported by studies in human growth (Harrison \& Schmitt 1989): when comparing coefficients of variation $(\mathrm{CV})$ in growth in height in different countries, populations living under more adverse conditions (e.g. in India and Thailand) generally have larger $\mathrm{CVs}$ than the populations living under affluent conditions (e.g., in the UK). According to Harrison, Maya children born and raised in Guatemala should not only differ in mean height from migrant Maya children, born and raised in US locations, but they should also differ in height distribution. This is not the case. 
Neither the data on migrant Maya height, nor the data on Bangladeshi children, nor historic observations in Japanese children (Spier 1929) support an environmental adversity hypothesis. Regardless of whether a population is short or tall, within group height difference between the tallest and the shortest remained unchanged.

The idea of some additional social regulation in height that narrows height variation toward the mean, appears straight forward. Social interactions and group behaviour have long been studied. Turner \& Oakes (1986) discussed social selfconcepts in their social identity theory, and showed that the system of cognitive representations of self is based upon comparisons with other people and relevant to social interaction. Group membership correlates with emotional, evaluative and other psychological parameters. Turner \& Oakes employed the concept of a 'self-categorization theory' to explain the social-psychological basis of group phenomena, and to identify the mechanisms by which individuals become unified into a psychological group. "Group identification" and "identity signalling" facilitate in-group favouritism, and shape common goals and social norms. Conflicts of group interests not only create antagonistic intergroup relations, but also heighten identification with, and positive attachment to the in-group (Tajfel \& Turner 1986). In relevant intergroup situations, individuals will not interact as individuals, on the basis of their individual characteristics or interpersonal relationships, but as members of their groups.

These observations are grounded in what is today called Social Network Theory, a field of inquiry that studies how people relate to each other, interact with each other, and affect each other. The connectivity between people has been shown to show clustering of social-behavioral properties such as happiness, loneliness, depression, sleep, drug use, divorce, sexuality and sexual orientation, political orientation, and tastes in movies, music, and books. These types of networks are not surprising, but less expected are findings of networks of social contagion in the 'spread' of food consumption, obesity, smoking, alcohol consumption, likelihood of health screening, cooperative behavior, influenza (Christakis \& Fowler 2013). These associations are social in nature - they do not depend on genetic relatedness between people - but, are of biological importance in that they produce phenotypic variation that leads to elevated risk for morbidity and mortality. A meta-analysis of 148 studies found that structural aspects of the social network itself, that is, the degree of an individual's integration in a social network, is as important as the functional consequences of membership, such as smoking or drug use (Holt-Lunstad et al. 2010). These authors write that, "social relationships exert an independent influence on risk for mortality comparable with well-established risk factors for mortality" (p. 12).

Group phenomena have long been studied in animals, and it has been shown that growth rates of mammals may vary in relation to their social environment. Huchard et al. (2016) showed in wild Kalahari meerkats (Suricata suri- catta) that achieving a dominant position within the group is a direct stimulus to growth, and that individuals can adjust their growth to the size of their closest competitor. Equally important to emphasize is that growth adjustments toward larger body size happen before there is an increase in food intake. The authors discussed strategic growth adjustments and competitive growth not only in these, but also in other social mammals, including primates and humans.

These data support the view that an individual's position within the group is a regulator and potential stimulus for growth. Aßmann \& Hermanussen (2013) used a Bayesian approach to model data from a longitudinal study of school children and adolescents from Zurich, Switzerland, and found evidence for a growth regulation that operates during adolescence and adjusts individual height toward the average height of their peers, i.e. her/his immediate community (Fig. 2). They wrote, "the smaller the adolescent is compared with past mean average height (of the community), the more the adolescent grows during puberty". Conversely, taller than average adolescents will grow less. The net outcome is that the distribution of heights of members of a community (or a social network) is narrow and will cluster toward the mean value ("community effect on height"). People may simply be short because their friends and neighbours are short, or tall because their friends and neighbours are tall.

A recent analysis of Polish school children further supported this idea. Koziel \& Gomula (2016) showed in 1810 children aged 14 years decreases in height and BMI variance within school classes. Hermanussen \& Scheffler (2016) further elaborated on these findings by providing historic evidence that stature may serve as a social signal. From this literature we derive our hypothesis that migrant children adjust their height growth toward the mean of the recipient social network. They start perceiving themselves as members among peers within their new social networks and they grow toward the average height of their hosts via the processes of competitive growth and strategic growth adjustments (Fig. 2).

The mechanism that allows for strategic growth adjustments and competitive growth and for the direct stimulatory effect of dominance on growth remains unclear. Preliminary data on IGF-1 in alpha males in primates (Sapolsky \& Spencer 1997) and on the effect of sport success in humans (Bogin et al. 2015) suggest involvement of the IGF-1-growth hormone axis to play a role in this regulation. IGF-1, as one of the most potent regulators of human growth, closely interacts with the mammalian target of rapamycin (mTOR) signalling pathway that has recently been reviewed by Saxton \& Sabatin (2017). mTORC1 is a master growth regulation pathway that is sensitive to nutrition deficits. mTORC1 specifically senses amino acid deficiency and represses protein and lipid synthesis and cellular growth in the state of starvation (Efeyan et al. 2015). This explains findings of Semba et al. (2016) who showed that low serum concentrations of all nine essential amino acids, with conditionally essential 
amino acids (arginine, glycine and glutamine), non-essential amino acids (asparagine, glutamate and serine) and six different sphingolipids are associated with child stunting in Malawi. The study also found significant differences in phosphatidylcholines which are involved in chondrogenesis, a major determinant of linear growth, underscoring the causal association of poor growth in the state of under-nutrition and inadequate dietary intake of essential amino acids and choline. These findings need to be taken into consideration when discussing growth in migrant children from nutritional deprived regions. These data however, do not throw light onto the mechanisms that allow for growth adjustments and competitive growth in migrant children that were appropriately nourished and yet, catch-up toward their new hosts, and to off-spring of violent, oppressive or military and colonial migrants who diverge from the conquered toward greater mean height.

\section{Conclusion}

There is no singular characteristic pattern of migrant growth. This partially derives from the definitions of how to define the status of a migrant. As migration usually directs towards more prosperous socio-economic conditions, it is difficult to unambiguously separate environmental, nutritional, health related, and other physical effects on migrants from effects mediated by their social, cultural and structural assimilation. Migrant assimilation usually starts quickly. Migrant children perceive themselves as members among peers within their new social networks. But migrants may not only simply assimilate in height. They may also significantly surpass height of their host population as observed in colonial rulers, or otherwise psychologically, politically or economically dominating groups. Observations in animals on strategic growth adjustments and competitive growth as relevant growth regulators strengthen the concept of social connectedness being involved in the regulation also of migrant growth.

Acknowledgements: This study was supported by the Auxological Society. Publication of the manuscripts of this supplement volume has been made possible with grateful support of Lilly Deutschland $\mathrm{GmbH}$.

\section{Declaration of interest statement}

The authors report no conflicts of interest.

\section{References}

Aguayo, V.M. \& Menon, P. (2016): Stop stunting: improving child feeding, women's nutrition and household sanitation in South Asia. - Maternal and Child Nutrition 12 (Suppl. 1): 3-11.
Ashbranner, B. \& Conklin, P. (1986): Children of the Maya. Dodd, Mead, New York.

Aßmann, C. \& Hermanussen, M. (2013): Modeling determinants of growth: evidence for a community-based target in height? Pediatr. Res. 74: 88-95.

Baldwin, B.T. (1924): The use and abuse of weight-height-age tables as indexes of health and nutrition. - J. Am. Med. Ass. I. Vol. 82: 2-6.

Boas, F. (1912): Changes in the bodily form of descendants of immigrants. - Am. Anthropol. 14: 530-563.

Boersma, B. \& Wit, J.M. (1997): Catch-up growth. - Endocr. Rev. 18: $646-661$.

Bogin, B. (1988): Rural-to-Urban Migration. - In: Mascie-Taylor, C.G.N. \& Lasker, G.W. (eds): Biological Aspects of Human Migration. - Cambridge University Press, Cambridge, pp. 90-129.

Bogin, B. \& Loucky, J. (1997): Political economy and physical growth of Guatemala Maya children living in the United States. - Am. J. Phys. Anthropol. 102: 17-32.

Bogin, B., Smith, P.K., Orden, A.B., Varela Silva, M.I. \& Loucky, J. (2002): Rapid change in height and body proportions of Maya American children. - Am. J. Hum. Biol. 14: 753-761.

Bogin, B., Hermanussen, M., Blum, W.F. \& Aßmann, C. (2015): Sex, Sport,IGF-1 and the Community Effect in Height Hypothesis. - Int. J. Environ. Res. Public Health 12: 4816-4832.

Boyd, E. (1980): Origins of the Study of Human Growth. University of Oregon Health Science Foundation, Eugene.

Burns, A. (1993): Maya in Exile. - Temple University Press, Philadelphia.

Campbell, D.I., McPhail, G., Lunn, P.G., Elia, M. \& Jeffries, D.J. (2004): Intestinal inflammation measured by fecal neopterin in Gambian children with enteropathy: association with growth failure, Giardia lamblia, and intestinal permeability. - J. Pediatr. Gastroenterol. Nutr. 39: 153-157.

Christakis, N.A. \& Fowler, J.H. (2013): Social contagion theory: Examining dynamic social networks and human behavior. Stat. Med. 32: 556-577.

Dangour, A.D., Watson, L., Cumming, O., Boisson, S., Che, Y., Velleman, Y., Cavill, S., Allen, E. \& Uauy, R. (2013): Interventions to improve water quality and supply, sanitation and hygiene practices, and their effects on the nutritional status of children. - Cochrane Database of Systematic Reviews, Issue 8, Art. No.: CD009382, doi: 10.1002/14651858.CD009382. pub2.

de Haas, J.H. (1931): Lichamelijke ontwikkeling en ziekten van de kinderen van het internaat der planters schoolvereeniging "brastagi". - Nederlands Tijdschrift voor Geneeskunde 75. IV.41: 5150-5163.

Dölen, G., Darvishzadeh, A., Huang, K.W. \& Malenka, R.C. (2013): Social reward requires coordinated activity of nucleus accumbens oxytocin and serotonin. - Nature 501 (7466): 179-84.

Efeyan, A., Comb, W.C. \& Sabatini, D.M. (2015): Nutrient-sensing mechanisms and pathways. - Nature 517 (7534): 302-310.

Floud, R. (1994): The height of Europeans since 1750: a new source for European economic history. - In: Komlos, J. (ed.): Stature, Living Standards, and Economic Development. - University of Chicago Press, Chicago, pp. 9-24.

Fredriks, A.M. (2004): Growth diagrams. - Fourth Dutch nationwide survey, Doctorial dissertation, Leiden, pp. 91-104. 
Fredriks, A.M., Buuren, S.V., Burgmeijer, R.J.F., Meulmeester, J.F., Beuker, R.J., Brugman, E., Roede, M.J., Verloove-Vanhorick, S.P. \& Wit, J.M. (2000): Continuing positive secular growth change in the Netherlands 1955-1997. - Ped. Res. 47: 316-323.

Garrow, J.S. \& Pike, M.C. (1967): The long term prognosis of severe infantile malnutrition. - Lancet 289 (7480): 1-4.

Gorter, F.J. \& de Haas, J.H. (1947): Gewicht en Lengte van 30.000 Schoolkinderen te Batavia. - Maandschrift voor Kindergeneeskunde 15: 154-202.

Goudet, S.M., Griffiths, P.L., Bogin, B. \& Madise, N.J. (2016): Interventions to tackle malnutrition and its risk factors in children living in slums: a scoping review. - Ann. Hum. Biol. 44: $1-10$.

Gratton, B., Gutmann, M.P. \& Skop, E. (2007): Immigrants, their children, and theories of assimilation: family structure in the United States, 1880-1970. - Hist. Fam. 12: 203-222.

Grupe, G., Christiansen, K., Schröder, I. \& Wittwer-Backofen, U. (2012): Anthropologie: Ein einführendes Lehrbuch. $-2^{\text {nd }}$ ed., Springer, Berlin, Heidelberg.

Harrison, G.A. (1963): Temperature adaptation as evidenced by the growth of mice. - Federation Proceedings 22: 691-698.

Harrison, G.A. \& Schmitt, L.H. (1989): Variability in stature growth. - Ann. Hum. Biol. 16: 45-51.

Henneberg, M. (2001): Secular trends in body height - indicator of general improvement in living conditions or of a change in specific factors? - In: Dasgupta, P. \& Hauspie, R. (eds): Perspectives in Human Growth, Development and Maturation. - Springer, Netherlands, pp. 159-167.

Hermanussen, M. (2013): Auxology: Studying human growth and development. - Schweizerbart, Stuttgart.

Hermanussen, M., Alt, C., Staub, K., Aßmann, C. \& Groth, D. (2014): The impact of physical connectedness on body height in Swiss conscripts. - Anthropol. Anz. 71 (4): 313-327. doi: 10.1127/0003-5548/2014/0466

Hermanussen, M., Aßmann, C., Staub, K. \& Groth, D. (2016): Monte Carlo simulation of body height in a spatial network. Eur. J. Clin. Nutr. 70: 671-678.

Hermanussen, M. \& Scheffler, C. (2016): Stature signals status: The association of stature, status and perceived dominance - a thought experiment. - Anthropol. Anz. 73 (4): 265-274. doi:10.1127/anthranz/2016/0698

Hermanussen, M. \& Wit, J.M. (2017): How Much Nutrition for How Much Growth? - Horm. Res. Paediatr. 88: 38-45.

Holt-Lunstad, J., Smith, T.B. \& Layton, J.B. (2010): Social relationships and mortality risk: a meta-analytic review. - PLoS Med. 7: e1000316.

Hossain, M., Choudhury, N., Adib Binte Abdullah, K., Mondal, P., Jackson, A.A., Walson, J. \& Ahmed, T. (2017): Evidence-based approaches to childhood stunting in low and middle income countries: a systematic review. - Arch. Dis. Child 102: 903-909. doi: 10.1136/archdischild-2016-311050.

Houghton, L.C., Cooper, G.D., Booth, M., Chowdhury, O.A., Troisi, R., Ziegler, R.G., Katki, H.A., Hoover, R.N. \& Bentley, G.R. (2014): Childhood environment influences adrenarcheal timing among first-generation Bangladeshi migrant girls to the UK. - PLoS One 9: e109200.

Huchard, E., English, S., Bell, M.B., Thavarajah, N. \& CluttonBrock, T. (2016): Competitive growth in a cooperative mammal. - Nature 533: 532-534.
Kanat, M., Heinrichs, M. \& Domes, G. (2014): Oxytocin and the social brain: neural mechanisms and perspectives in human research. - Brain Res. 1580: 160-171.

Keys, A., Brozek, J., Henschel, A., Mickelsen, O. \& Taylor, H.L. (1950): The Biology of Human Starvation. - University of Minnesota Press, Minneapolis.

Koch, E.W. (1935): Über die Veränderung menschlichen Wachstums im ersten Drittel des 20. Jahrhunderts. - Barth, Leipzig.

Komlos, J. \& Baur, M. (2004): From the tallest to (one of) the fattest: the enigmatic fate of the American population in the $20^{\text {th }}$ century. - Econ. Hum. Biol. 2: 57-74.

Komlos, J. \& Cuff, T. (eds) (1998): Classics in anthropometric history. - Scripta Mercaturae Verlag, St. Katharinen, Germany.

Kornienko, O., Clemans, K.H., Out, D. \& Granger, D.A. (2014): Hormones, behavior, and social network analysis: exploring associations between cortisol, testosterone, and network structure. - Horm. Behav. 66: 534-544.

Kornienko, O., Schaefer, D.R., Weren, S., Hill, G.W. \& Granger, D.A. (2016): Cortisol and testosterone associations with social network dynamics. - Horm. Behav. 80: 92-102.

Koziel, S. \& Gomula, A. (2017): Variation of height and BMI within school classes in 14-year-old children. - Anthropol. Anz. 74 (1): 77-80. doi: 10.1127/anthranz/2017/0702

Krzyżanowska, M. \& Mascie-Taylor, C.G. (2011): Geographical variation and migration analysis of height, weight and body mass index in a British cohort study. - J. Biosoc. Sci. 43: 733-749.

Landis, D. \& Alber, R.D. (eds) (2012): Handbook of Ethnic Conflict: International Perspectives. - International and Cultural Psychology. - Springer, New York.

Lasker, G.W. (1969): Human biological adaptability. - Science 166: $1480-1486$.

Loucky, J. (1996): Maya Americans: The emergence of a transnational community. - In: Hamilton, N. \& Chinchilla, N. (eds): Central Americans in California, Los Angeles. - Center for Multiethnic Studies and Transnational Studies, University of Southern California, pp. 30-34.

Lunn, P.G. (2000): The impact of infection and nutrition on gut function and growth in childhood. - Proc. Nutr. Soc. 59: 147-154.

Mascie-Taylor, C.G. \& Krzyżanowska, M. (2017): Biological aspects of human migration and mobility. - Ann. Hum. Biol. 30: $1-32$.

Modesti, P.A., Bianchi, S., Borghi, C., Cameli, M., Capasso, G. \& Ceriello, A. et al. (2014): Cardiovascular health in migrants: current status and issues for prevention. A collaborative multidisciplinary task force report. - J. Cardiovasc. Med. (Hagerstown) 15: 683-692.

Mouw, T., Chavez, S., Edelblute, H. \& Verdery, A. (2014): Bi-national Social Networks and Assimilation: A Test of the Importance of Transnationalism. - Soc. Probl. 61: 329-359.

NCD Risk Factor Collaboration (NCD-RisC) (2016): A century of trends in adult human height. - Elife 5: e13410.

Ngure, F.M., Reid, B.M., Humphrey, J.H., Mbuya, M.N., Pelto, G. \& Stoltzfus, R.J. (2014): Water, sanitation, and hygiene (WASH), environmental enteropathy, nutrition, and early child development: making the links. - Ann. N.Y. Acad. Sci. 1308: $118-128$.

Ponzi, D., Zilioli, S., Mehta, P.H., Maslov, A. \& Watson, N.V. (2016): Social network centrality and hormones: The interaction 
of testosterone and cortisol. - Psychoneuroendocrinology 68: $6-13$.

Proos, L.A. (2009): Growth and development of Indian children adopted in Sweden. - Indian J. Med. Res. 130: 646-650.

Ravenstein, E.G. (1885): The Laws of Migration. - Journal of the Statistical Society of London 48 (2): 167-235, available at: http://lewishistoricalsociety.com/wiki2011/tiki-read_article. php? articleId $=28$.

Redlefsen, T., Commentz, J., Meigen, C. \& Hermanussen, M. (2007): Reference values for height, weight and body mass index of German born Turkish children. - Anthropol. Anz. 65 (3): 263-274.

Rogawski, E.T., Westreich, D.J., Adair, L.S., Becker-Dreps, S., Sandler, R.S., Sarkar, R., Kattula, D., Ward, H.D., Meshnick, S. \& Kang, G. (2015): Early Life Antibiotic Exposure Is Not Associated with Growth in Young Children of Vellore, India. J. Pediatr. 167: 1096-1102.e3.

Sapolsky, R.M. \& Spencer, E.M. (1997): Insulin-like growth factor I is suppressed in socially subordinate male baboons. - Am. J. Physiol. 273 (4/2): R1346-R1351.

Saxton, R.A. \& Sabatini, D.M. (2017): mTOR Signaling in Growth, Metabolism, and Disease. - Cell. 168 (6): 960-976.

Schlesinger, E. (1926): Das Wachstum des Kindes. - Springer, Berlin, Heidelberg.

Semba, R.D., Shardell, M., Sakr Ashour, F.A., Moaddel, R., Trehan, I., Maleta, K.M., Ordiz, M.I., Kraemer, K., Khadeer, M.A., Ferrucci, L. \& Manary, M.J. (2016): Child Stunting is Associated with Low Circulating Essential Amino Acids. - EBioMedicine 6: 246-252.

Smith, P.K., Bogin, B., Varela Silva, M.I., Orden, A.B. \& Loucky, J. (2002): Does immigration help or harm children's health?The Mayan case. - Social Science Quarterly 83: 994-1002.

Spier, L. (1929): Growth of Japanese children born in America and in Japan. - University of Washington, Publication in Anthropology 3: 1-29.
Tajfel, H. \& Turner, J.C. (1986): The social identity theory of intergroup behaviour. - In: Worchel, S. \& Austin, W.G. (eds): Psychology of intergroup relations. $2^{\text {nd }}$ ed. - Nelson-Hall, Chicago, pp. 7-24.

Turner, J.C. \& Oakes, P.J. (1986): The significance of the social identity concept for social psychology with reference to individualism, interactionism and social influence. - Brit. J. Soc. Psychol. 25: 231-252.

van der Merwe, L.F., Moore, S.E., Fulford, A.J., Halliday, K.E., Drammeh, S., Young, S. \& Prentice, A.M. (2013): Long-chain PUFA supplementation in rural African infants: a randomized controlled trial of effects on gut integrity, growth, and cognitive development. - Am. J. Clin. Nutr. 97: 45-57.

Waldinger, R. (2008): Between 'here' and 'there': Immigrant crossborder activities and loyalties. - International Migration Review 42: 3-29.

WHO Multicentre Growth Reference Study Group (2006): WHO child growth standards based on length/height, weight and age. - Acta Paediatr. Suppl. 450: 76-85.

Williams, E.A., Elia, M. \& Lunn, P.G. (2007): A double-blind, placebo-controlled, glutamine-supplementation trial in growthfaltering Gambian infants. - Am. J. Clin. Nutr. 86: 421-427.

Zielińska, D. (1991): Is there a selective rural-urban migration in respect to height and weight? - Am. J. Hum. Biol. 3: 363-368.

Manuscript received: 24 October 2017

Revisions required: 2 November 2017

Revised version received: 7 November 2017

Accepted: 13 November 2017 